\title{
The effect of obligate hyperparasitoids on biological control: Differential vulnerability of primary parasitoids to hyperparasitism can mitigate trophic cascades
}

Robert S. Nofemela*

Insect Ecology Division, ARC-Plant Protection Research Institute, Private

Bag X134, Queenswood 0121, South Africa Department of Zoology \&

Entomology, University of Pretoria, Private Bag X20, Pretoria 0028,

South Africa.*Email: NofemelaR@arc.agric.za

\section{Highlights}

-Cotesia vestalis was a dominant primary parasitoid of Plutella xylostella.

-It was also a secondary host to three obligate hyperparasitoid species.

-At low hyperparasitism, C. vestalis limited hosts available to competitors.

-As C. vestalis population declined, competitors parasitized more of available hosts.

-Species that are invulnerable to hyperparasitism took over role of the vulnerable.

\section{Graphical abstract}
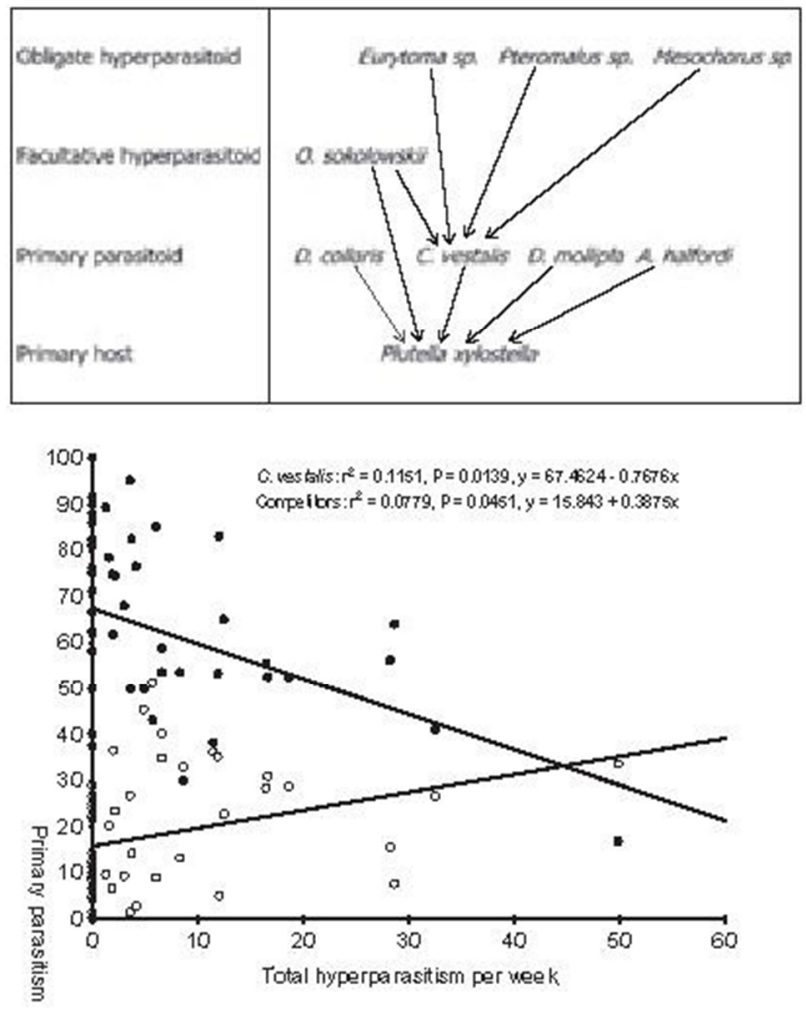
Abstract : Obligate hyperparasitoids are widely considered an important ecological disturbance to biological control of insect pests, as they develop at the expense of primary parasitoids. However, supporting evidence is largely derived from direct trophic interactions in simple food webs. Yet, a multitude of insect pest populations simultaneously support development of several primary parasitoid species in horticultural and natural systems. Since primary parasitoid species in a community can differ in vulnerability to obligate hyperparasitoids, it is desirable to establish if the invulnerable primary parasitoids can take advantage of reduced competition from affected species by increasing their contribution to total primary parasitism levels thereby mitigating effects of hyperparasitism on biological control. To investigate this question, populations of the diamondback moth, Plutella xylostella (Linnaeus) (Plutellidae), its primary parasitoids and hyperparasitoids were monitored on unsprayed cabbage plots at weekly intervals over six consecutive years. Cotesia vestalis (Haliday) (Braconidae), a dominant primary parasitoid in this system, was a secondary host to three obligate hyperparasitoids: Mesochorus sp. (Ichneumonidae), Eurytoma sp. (Eurytomidae) and Pteromalus sp. (Pteromalidae). The higher efficiency of $\mathrm{C}$. vestalis in utilizing younger host larvae at lower hyperparasitism levels limited host availability to other major primary parasitoids. But, as hyperparasitism levels increased and its populations declined, populations of Oomyzus sokolowskii (Kurdjumov) (Eulophidae) and Diadromus collaris (Gravenhorst) (Ichneumonidae) increased significantly as they parasitized a greater proportion of available hosts. As a consequence, the impact of hyperparasitoids did not result in trophic cascades, as their impact on total primary parasitism levels and infestation levels was insignificant. This study shows that primary parasitoid species that are invulnerable to hyper-parasitism can take over the function of vulnerable ones in communities where interspecific interactions among species are strong. Thus, an approach that considers both direct and indirect effects of hyperparasitoids in primary parasitoid communities improves our understanding of the net impact of hyperparasitism on biological control of insect pests.

Keywords: Plutella xylostella Infestation level Primary parasitism Hyperparasitism Top-down effect Developmental traits Functional diversity

\section{Introduction}

Biological control theory suggests that consumer species can effectively suppress their host or prey populations (Hairston et al., 1960; Crawley, 1989). However, the strong top-down effect of consumers not only influences the population size of prey/hosts, but can indirectly influence population densities of species in lower trophic levels. This propagation of strong effects of higher-order consumers through the food web is called a trophic cascade (Polis et al., 2000). In a simple food web involving a host plant - an insect herbivore - a primary parasitoid, high parasitism of the herbivore population benefits the host plant if infestation levels are reduced (Murdoch and Briggs, 1996; Hawkins and Cornell, 1999; Matsumoto et al., 2003). Although primary parasitoids are widely utilized for biological control of insect pests (DeBach and Rosen, 1991), they do not occupy the highest trophic level. Due to direct relevance of trophic cascades to biological control practice, the effect of secondary parasitoids (hereafter referred to as 'hyperparasitoids') on efficiency of primary parasitoids is an important topic in biological control (Rosen, 1981; Rosenheim, 1998; Sullivan and Völkl, 1999).

Four types of hyperparasitoids are described (Sullivan and Völki, 1999; Walter and Abeeluck, 2006); but only two types (i.e., facultative and obligate) are found where Lepidoptera are plant pests (Sullivan and Völk1, 1999), which is a focus of this study. Facultative hyperparasitism is a form of omnivory, where a parasitoid feeds on two trophic levels by acting both as a primary parasitoid and a hyperparasitoid (Brodeur, 2000). However, this group of hyperparasitoids is not considered detrimental to biological control, except where they selectively parasitize primary parasitoids more than the insect pest population (Moore and Kfir, 1995; Pérez-Lachaud et al., 2004). In contrast, obligate hyperparasitoids only reproduce on primary parasitoids, and this direct impact on primary parasitoid populations has made them the most studied hyperparasitoid group (Clausen, 1972; Sullivan and Völkl, 1999). They are divided into two subcategories: (1) those attacking larvae of primary parasitoids through the body of insect pests and, (2) those attacking primary parasitoid pupae outside the body of insect pests (Sullivan and Völk1, 1999). The presence of both subcategories in a food web can alter the food web structure if those 
species attacking primary parasitoid pupae also parasitize species attacking larval stages (Carew and Sullivan, 1993; Brodeur, 2000).

A majority of studies have shown that presence of obligate hyperparasitoids increases herbivory as insect pest populations are often released from the strong top-down effect of primary parasitoids (Bourchier and Nealis, 1992; Eichhorn, 1996; Boenisch et al., 1997; Lei and Hanski, 1997; Rosenheim, 1998; Brodeur, 2000; Schooler et al., 2011). Further, obligate hyperparasitoids can leave cues on the plant surface that may increase dispersal probability of primary parasitoids, which further reduces mortality of insect pests (Höller et al., 1993; van Veen et al., 2001). However, other studies have shown that the impact of obligate hyperparasitoids is not always sufficiently large to result in trophic cascades (Cameron and Walker, 2002; Roltsch et al., 2006; Araj et al., 2009) due to: (1) the ability of some primary parasitoids to modify the behavior of parasitized hosts (Brodeur and McNeil, 1992; Tanaka and Ohsaki, 2006, 2009), (2) density-independent hyperparasitoid aggregation (Weseloh, 1986; Ayal and Green, 1993; Schooler et al., 1996; Müller and Godfray, 1998), and (3) lower reproductive potential of obligate hyperparasitoids compared to their primary parasitoid hosts (Brodeur, 2000).

Although these studies provided important basic knowledge of differential impact of obligate hyperparasitoids on biological control of insect pests, they largely investigated this indirect effect using direct trophic interactions. Yet, a multitude of insect herbivore populations are known to simultaneously support development of several primary parasitoid species in natural and horticultural systems (Godfray, 1994; Hawkins, 1994; Müller et al., 1999). Although obligate hyperparasitoids are not host-specific, they do not just attack any primary parasitoid species as their host range is restricted by developmental traits of their hosts (Grasswitz and Reese, 1998; Chow and Mackauer, 1999; Schwarz and Shaw, 2000; Day, 2002). Thus, primary parasitoid species that perform the same function in a community (e.g., egg, larval or pupal parasitoids, and thus are functionally redundant; Loreau, 2004; Casula et a1., 2006) may be equally vulnerable to obligate hyperparasitoids that require their shared traits (Clausen, 1972). However, primary parasitoids that attack different life stages of a common host population (i.e., they perform different functions in the community, and thus are functionally complementary; Wilson et al., 1999; Cardinale et al., 2003; Veddeler et al., 2010) usually have different suites of hyperparasitoids. Thus, the developmental traits of primary parasitoid species in a community determine whether a given obligate hyperparasitoid produces species-level or community-level trophic cascades (see Polis et al., 2000; Schmitz et al., 2000).

The life stages of the diamondback moth, Plutella xylostella (Linnaeus) (Lepidoptera: Plutellidae), are attacked by several species of primary parasitoids in South Africa, of which Cotesia vestalis (Haliday) [= Cotesia plutellae (Kurdjumov)], a solitary koinobiont larval parasitoid, is the most dominant. However, its larval and pupal stages are in turn attacked by three species of obligate hyperparasitoids (Waladde et al., 2001; Mosiane et al., 2003; Smith, 2004; Nofemela and Kfir, 2005). In this study, I use long-term data sets to establish whether: (1) the effect of obligate hyperparasitoids on $C$. vestalis populations are significantly high to limit its impact on $P$. xylostella, (2) the invulnerable primary parasitoid species increase their contribution to total parasitism levels as populations of $C$. vestalis decline, and (3) the population increase of invulnerable primary parasitoids effectively counteracts the effect of hyperparasitoids on $C$. vestalis.

\section{Materials and methods}

\subsection{Study area}

The study reported here was conducted on a research farm belonging to the ARC-Institute for Industrial Crops at Brits $\left(25^{\circ} 59^{\prime} \mathrm{S}, 27^{\circ} 76^{\prime} \mathrm{E}\right.$, altitude $\left.1082 \mathrm{~m}\right)$, North West Province of South Africa. The Brits municipality area is within the Highveld, i.e., a high plateau inland region characterized by temperate climate and summer rainfall (Rutherford et al., 2006). The study site is within the Marikana Thornveld, a component of the Savannah Biome, where dominant natural vegetation is Acacia karroo. The soil type is mainly vertic melanic clays with some dystrophic or mesotrophic plinthic catenas and some freely drained, deep soils. Long-term annual precipitation is between 600 and $700 \mathrm{~mm}$, and mean maximum and minimum temperatures are $35.3^{\circ} \mathrm{C}$ and $3.3^{\circ} \mathrm{C}$ for January and June, respectively (Rutherford et al., 2006). Several species of wild Brassica species are abundant during rainy months in South Africa (Jordaan, 1993), and these are known to be important reservoirs for P. xylostella and its parasitoids that later move into cultivated crucifers (Ullyett, 1947; Kahuthia-Gathu et al., 2009). Cabbage [Brassica oleraceae variety capitata (Linnaeus) (Brassicaceae)] is one of the major crops grown under irrigation in farms within $5 \mathrm{~km}$ radius of the study site. Commercial growers transplant cabbage seedlings on 
several hectares, usually 25,000 cabbages/ha, every week during summer and autumn, but few hectares are planted during winter and summer months (Multi-plant nursery, Brits, personal communication). It appears that the major reason for transplanting fewer cabbages during cool seasons is influenced by slower developmental rate of the crop, which affects produce flow rate from the farm. Since immature Brassica plants were always present at any given moment at a landscape level around the study site, the cabbage fields are assumed to be connected [i.e., metapopulation theory] due to free movement of P. xylostella and its parasitoids between the farms (Vandermeer and Carvajal, 2001; Desouhant et al., 2003; Gichini et al., 2008).

\section{2. $\quad$ Monitoring of P. xylostella infestations and its parasitoids}

Cabbage seedlings (between 2000 and 2500) were transplanted three consecutive times per year, from February 2002 to January 2008, at a plant spacing of $0.5 \mathrm{~m}$ within and $1 \mathrm{~m}$ between rows. Standard agronomic practices that included plowing, irrigation, fertilization, and weeding were followed in each crop, but without application of insecticides. For each crop, monitoring of P. xylostella infestations (1.e., larvae and pupae) and its parasitoids was initiated two weeks after cabbage transplants. In subsequent plantings, a new crop was prepared next to the old one five weeks before harvest of the current crop, and two weeks later scouting on the older plot was terminated and begun on the new plot. This practice ensured that investigations were continually conducted on crops of reasonably good quality. Therefore, until it was completely harvested and remaining plants plowed under, the older crop served as a reservoir for $P$. xylostella and its parasitoids at a local scale. One experimental plot was monitored at any given time and a total of 18 plots were monitored during the study period.

At weekly intervals, leaves of 30 randomly selected plants in each crop were thoroughly inspected and numbers of $P$. xylostella larvae, pupae, and its parasitoid pupae found in each plant were recorded. Since no egg parasitoid species have been recorded from P. xylostella in South Africa (Kfir, 1997), parasitism levels were determined from samples of host larvae and pupae, and pupae of its parasitoids. However, 1 st and 2 nd instar larvae were not sampled for all known $P$. xylostella egg-larval and larval parasitoids complete their larval development once the hosts have reached the fourth instar. Thus, parasitism of $\mathrm{P}$. xylostella eggs and larvae accumulates over the larval instars (Nofemela and Kfir, 2005, 2008). Further, sampling of host instars that are still vulnerable to parasitism is inappropriate, as it tends to grossly underestimate parasitism levels (van Driesche et al., 1991). Depending on the number of cabbages that were transplanted and season, the number of sampled plants during summer and autumn accounted for $14.4-18 \%$ of plant population, and 19.2-24\% of plant population during winter and spring. Thus, sampling hardly influenced population densities of the pest and its parasitoids.

\subsection{The determination of primary parasitism and hyperparasitism \\ levels of P. xylostella}

The field-collected samples were maintained in the insectary of the ARC-Plant Protection Research, Rietondale campus $\left(25^{\circ} 44^{\prime} \mathrm{S}, 18^{\circ} 13^{\prime} \mathrm{E}\right)$, in Pretoria, at $25 \pm 1^{\circ} \mathrm{C}, 65 \pm 5 \%$ rh., and L16: D8 photo-period. The larvae were provided with sections of fresh cabbage leaves and held individually in Petri dishes. The leaves were replaced every second day until all the larvae pupated or parasitoid pupae formed. The samples of P. xylostella pupae and parasitoid pupae were confined individually in ventilated glass vials $(2.5 \times 10 \mathrm{~cm})$. All emergent parasitoids were identified and their incidence determined. Voucher specimens were deposited in the National Collection of Insects, Biosystematics Division, ARC-Plant Protection Research Institute, Pretoria. Parasitism (primary and hyperparasitism) was calculated as the percentage of emergent parasitoids out of total samples of P. xylostella larvae and pupae, and parasitoid pupae. Thus, the 1mpact of primary parasitoids on P. xylostella population density was determined from parasitism of corresponding infestation levels. However, samples that died of unknown causes were excluded from calculations of parasitism.

\subsection{Data analysis}

One-way analysis of variance (ANOVA) was used to compare the incidence of the different primary parasitoid and hyperparasitoid species. Where significant differences were detected between incidences of the parasitoids, the means were compared using Fisher's protected least significance (LSD) test. Using mean values obtained over 6 years for each corresponding week (i.e., from week 1 in February to week 52 in January), linear regression analyses were performed to determine the influence of hyperparasitism on C. vestalis population densities over the course 
of the year, and the responses of unaffected primary parasitoid species populations as hyperparasitism levels increase. For all statistical analyses, the level of significance was set at $5 \%$ and the analyses were performed using Statistica (2012).

\section{Results}

Out of the 4476 samples of P. xylostella larvae and pupae, and pupae of primary parasitoids [i.e., the larval parasitoids C. vestalis and Apanteles halfordi (Ullyett) (Braconidae), and the tarval-pupal parasitoid Diadegma mollipla (Holmgren) (Ichneumonidae)] collected during this study, a total of four primary parasitoid species and a facultative hyperparasitoid (Fig. 1) and three species of obligate hyperparasitoids (Fig. 2) were recorded.

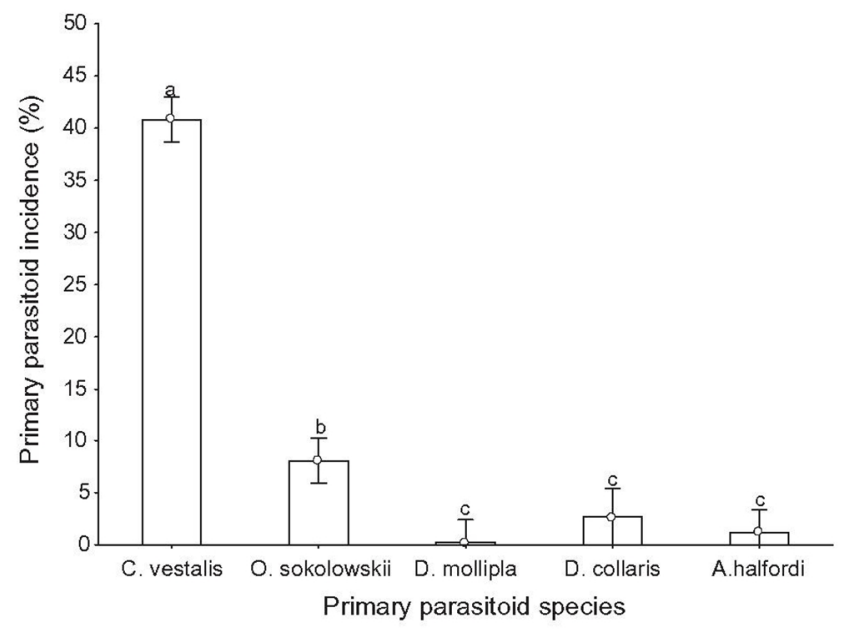

Fig. 1. The mean incidence of primary parasitoid species and the facultative hyperparasitoid Oomyzus sokolowskii on Plutella xylostella on unsprayed cabbage during February 2002-January 2008. Bars with the same letter indicate insignificant differences among means [Fisher's protected LSD test, $P>0.05$ ].

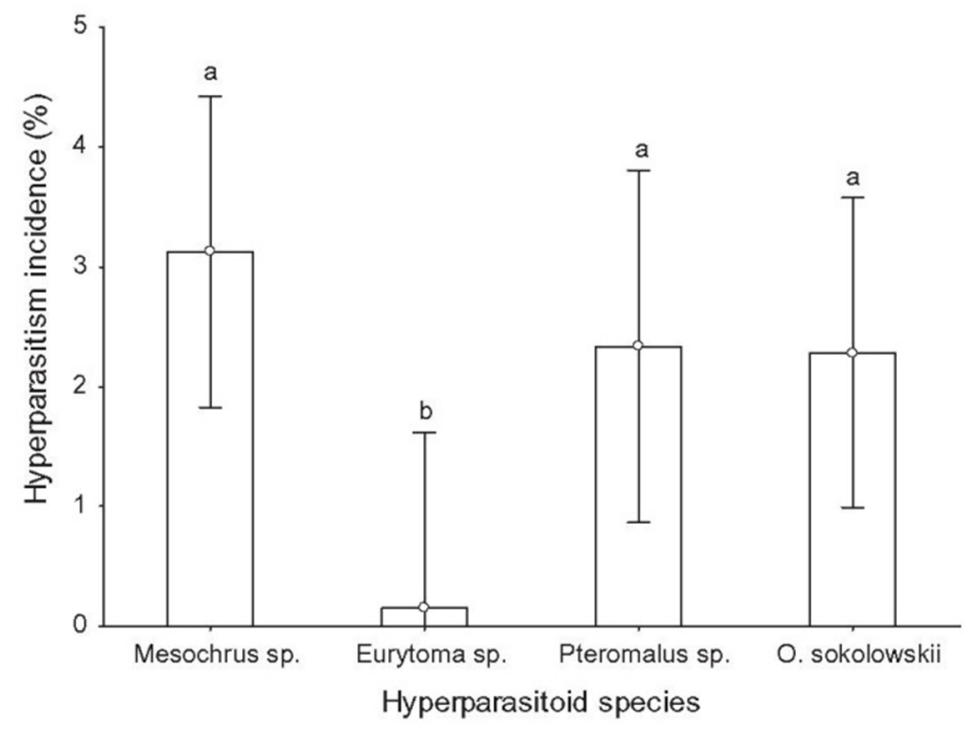

Fig. 2. The mean incidence of obligate hyperparasitoids and the facultative hyperparasitoid Oomyzus sokolowskii on Cotesia vestalis pupae on unsprayed cabbage during February 2002-January 2008. Bars with the same letter indicate insignificant differences among means [Fisher's protected LSD test, $P>0.05$ ]. 
The incidence of the primary parasitoid species differed greatly $(\mathrm{F} 4,1128=235.73 ; \mathrm{P}<0.001)$ on $P$. xylostella population with $C$. ves-talis dominating the primary parasitoid community followed by the facultative hyperparasitoid Oomyzus sokolowskii (Kurdjumov) (Eulophidae), a larval-pupal parasitoid (Fig. 1). This result is in agreement with previous studies on biological control of P. xylostella in South Africa (Kfir, 1997; Waladde et al., 2001; Mosiane et al., 2003; Smith, 2004; Nofemela and Kfir, 2005, 2008).

Although 0 . sokolowskii may attack $C$. vestalis larvae inside the primary host (Mahmood et al., 2003; Shi and Liu, 2003), it is considered more of a primary parasitoid than a hyperparasitoid in South Africa (Nofemela and Kfir, 2008), and in few other countries (Jamaica: Alam, 1992; Cape Verde: Cock, 1983). This view is upheld in this study for it attacked significantly $(\mathrm{t}=43206$; d.f. $=443 ; P<0.001)$ more $P$. xylostella (mean $\pm \mathrm{SD}=8.0574 \pm 15.9473)$ than $C$. vestalis $(2.2841 \pm$ 11.2639). The realized clutch size of $\mathbf{0}$. sokolowskii was significantly higher $(\mathrm{t}=5.3186$; $\mathrm{df} .=$ 184; $P<0.001)$ from $P$. xylostella pupae $(9.0693 \pm 3.399)$ than from $C$. vestalis pupae $(4.0 \pm$ 1.6833). The primary host density influences levels of hyper-parasitism by facultative hyperparasitoids, and consequently their impact on primary parasitoid populations in some systems (Borer et al., 2003), but hyperparasitic activity of $\mathbf{0}$. sokolowskii was independent $\left(\mathrm{r}^{2}=\right.$ $\left.0.0144 ; \mathrm{F}_{1,50}=0.7296 ; \mathrm{P}=0.3971 ; \mathrm{y}=10.6127-0.0451\right)$ of $\mathrm{P} . x y$ lostella infestations in this study.

The impact of $\mathbf{0}$. sokolowskii on $C$. vestalis populations was similar to that of obligate hyperparasitoids: Mesochorus sp. (Ichneumonidae) $(3.1263 \pm 0.66)$ and Pteromalus sp. (Pteromalidae) $(2.3345 \pm 0.7497)$ whose incidence was significantly higher $(\mathrm{F} 3,707=3.116 ; \mathrm{P}=$ 0256; Fig. 2) than Eurytoma sp. (Eurytomidae) $(0.1503 \pm 0.7497)$. Mesochorus sp. attacks $C$. vestalis larvae through the body of P. xylostella aided by its long ovipositor, and its offspring completes pupal development inside pupae of C. vestalis (Clausen, 1972; Kfir, 1997). Pteromalus sp. and Eurytoma sp. directly attack pupae of C. vestalis (Nofemela and Kfir, 2005).

The obligate hyperparasitoids were active for most of the year, except during winter months (June-August), albeit generally at low levels individually (Fig. 2), but their combined average impact (which includes 0. sokolowskii) on C. vestalis populations was significant $\left(\mathrm{r}^{2}=0.1151\right.$; $\mathrm{F}_{1,50}=6.5016 ; \mathrm{P}<0.0139 ; y=67.4624-0.7676 \mathrm{x}$; Fig. 3 ) during periods of high activity. Since P. xylostella egg and egg-larval parasitoids are rare in South Africa (Kfir, 1997), the higher efficiency of $C$. vestalis in utilizing young host larvae (Nofemela, 2004) can limit availability of healthy hosts for primary parasitoids attacking older larvae and advanced life stages. The primary parasitoids that took advantage of decreasing. $C$. vestalis population density by increasing their populations, as hyperparasitism levels increased were 0. sokolowskii $\left(\mathrm{r}^{2}=\right.$ $\left.0.2513 ; F_{1}, 50=16.7817 ; \mathrm{P}<0.001 ; y=5.9518+0.5113 \mathrm{x}\right)$ and Diadromus collaris (Gravenhorst) (Ichneumonidae), a pupal parasitoid, $\left(\mathrm{r}^{2}=0.1592 ; \mathrm{F}_{1}, 47=8.8959 ; \mathrm{P}=0.0045 ; y=\right.$ $1.3172+0.167 \mathrm{x})$. Thus, a significantly negative relationship $\left(\mathrm{r}^{2}=0.3517 ; \mathrm{F}_{1}, 50=27.1276 ; \mathrm{P}<\right.$ $0.001 ; y=41.0434-0.3639 \mathrm{x}$ ) between incidence of $\mathrm{C}$. vestalis and the two major primary parasitoids was observed.

While performance of $\mathbf{0}$. sokolowskii and D. collaris was clearly impeded by the high efficiency of $C$. vestalis at low hyperparasitism levels, but $D_{2}$ mollipla $\left(\mathrm{r}^{2}=0.0000 ; \mathrm{F}_{1}, 50=\right.$ $0.0001 ; \mathrm{P}=0.9921 ; y=0.1955+0.0001 \mathrm{x})$ and $\mathrm{A}$ halfordi $\left(\mathrm{r}^{2}=0.0022 ; \mathrm{F}_{1,50}=0.1081 ; \mathrm{P}=\right.$ $0.7437 ; y=0.8842+0.0109 \mathrm{x}$ ) populations remained low even when competition with $\mathrm{C}$. vestalis was reduced by hyperparasitism. In fact, D. mollipla was recorded in just 6 occasions and A halfordi in 25 out of the total of 254 scouting events where P. xylostella larvae were recorded.

The increases in populations of $\mathbf{0}$. sokolowskii and D. collaris were sufficiently large to counteract the impact of hyperparasitoids on $C$. vestalis populations, as hyperparasitism did not negatively influence total primary parasitism levels $\left(\mathrm{r}^{2}=0.0427 ; \mathrm{F} 1,50=2.2313 ; \mathrm{P}=0.1415 ; y\right.$ $=49.8155+0.6193 \mathrm{x})$ nor led to higher $\mathrm{P}$. xylostella infestations $\left(\wedge=0.0207 ; \mathrm{F}_{1,50}=1.0585 ; \mathrm{P}=\right.$ $0.3085 ; y=0.9209+0.0285 x)$. 


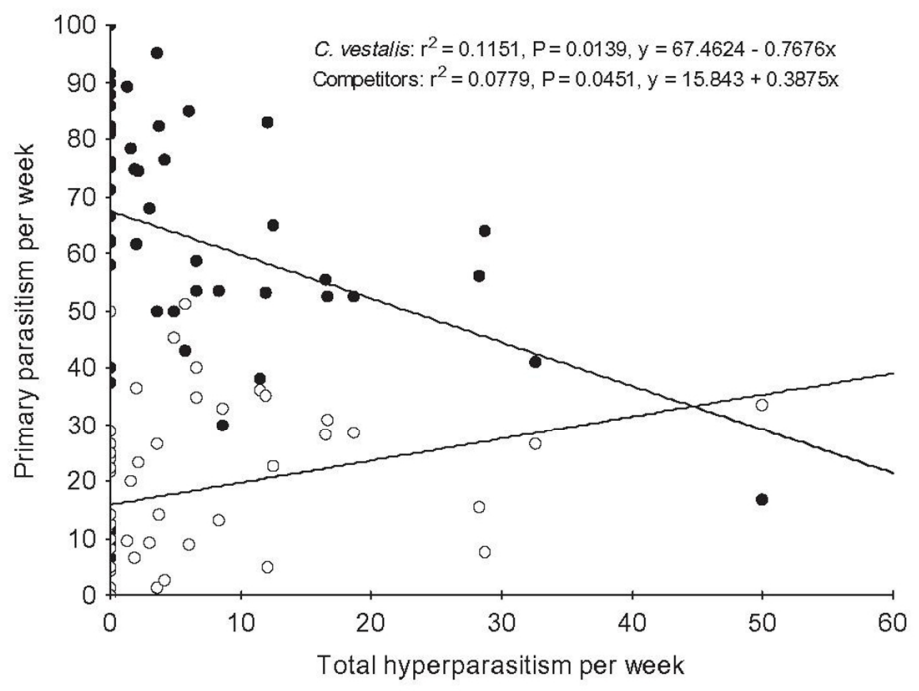

Fig. 3. The negative effect of hyperparasitism on Cotesia vestalis populations (solid circles) and the positive population response of some unaffected primary parasitoids (open circles) as hyperparasitism levels increased. Points in the graph represent corresponding averages per week over six years.

\section{Discussion}

The indirect influence of obligate hyperparasitoids on biological control of insect pests through direct impact on populations of primary parasitoids has grasped attention of biological control practitioners for decades (Rosen, 1981; Rosenheim, 1998; Sullivan and Völkl, 1999; Brodeur, 2000). Since the majority of studies showed that hyperparasitoids release insect pest populations from the strong top-down effect of primary parasitoids, it is generally recommended that introduction of hyperparasitoids should be avoided (Sullivan and Völkl, 1999). Although it is possible to exclude them during quarantine assessments of primary parasitoid consignments, primary parasitoids can acquire other obligate hyperparasitoid species once released in the field (Agricola and Fisher, 1991; Bourchier and Nealis, 1992; Kellogg et al., 2003). Since nothing can be done to exclude populations of obligate hyperparasitoids in nature, this predicament puts pressure of biological control practitioners to investigate ways of stabilizing biological control programmes in the light of ecological disturbance from obligate hyperparasitoids.

As a potential solution to this problem, I investigated the influence of differential vulnerability of primary parasitoid species in a community to obligate hyperparasitoids in mitigating effects of hyperparasitism on biological control using the P. xylostella natural system in South Africa as a model. In this system, only immature stages of the most abundant primary parasitoid species (C. vestalis) are vulnerable to resident obligate hyperparasitoid species (Waladde et al., 2001; Mosiane et al., 2003; Smith, 2004; Nofemela and Kfir, 2008). This study showed that as hyperparasitism levels increased, population density of $\mathrm{C}$. vestalis declined significantly. However, the impact of hyperparasitoids on C. vestalis populations did not negatively influence total primary parasitism levels nor led to high $\mathrm{P}$. xylostella infestations. This was a consequence of significant increases in population densities of unaffected primary parasitoid species (i.e., O. sokolowskii and D. collaris) that took advantage of the higher availability of unparasitized hosts as populations of $\mathrm{C}$. vestalis declined.

Since population densities of both $\mathrm{O}$. sokolowskii and D. collaris were negatively related to that of $\mathrm{C}$. vestalis, it can be inferred that the higher efficiency of $\mathrm{C}$. vestalis in utilizing young host larvae (Nofemela, 2004) limited availability of suitable hosts for O. sokolowskii and D. collaris at low hyperparasitism levels. It is widely observed that parasitoid species that attack early host life stages have an advantage of access to abundant host resource over those attacking advanced host life stages (Price, 1972; Chesson, 1991), except where the latter are able to utilize parasitized hosts (Briggs, 1993; Oishi and Sato, 2008). Since some potential hosts are missed by female parasitoids in the field (Godfray, 1994), the numerical dominance of the primary parasitoid species attacking early host life stages does not preclude coexistence with parasitoid species attacking advanced host life stages on the host population. As a consequence, changes in the population density of the dominant species have knock-on effect on population density of other species in the community such that as population density of the latter will increase when population density of the former decline (Müller and Godfray, 1999). Although D. collaris cannot utilize pupae already parasitized by other parasitoid species particularly larval-pupal 
parasitoids like O. sokolowskii (Liu et al., 2001), and thus it is at the mercy of hosts missed by parasitoids attacking P. xylostella larvae, of which the larval endoparasitoid C. vestalis is the most dominant, $\mathrm{O}$. sokolowskii can utilize some hosts containing $\mathrm{C}$. ves-talis larvae.

With few exceptions (Alam, 1992; Cock, 1983; Nofemela and Kfir, 2008; this study), the facultative hyperparasitic habit of $\mathrm{O}$. sokolowskii is considered to have a negative effect on $\mathrm{C}$. vestalis population density, and thus on total primary parasitism of P. xylostella (Talekar and $\mathrm{Hu}$, 1996). The ability of facultative hyperparasitoids to develop both as primary parasitoids and as hyperparasitoids is thought to give them an advantage over susceptible primary parasitoids (Rosenheim et al., 1995; Sullivan and Völkl, 1999; Pérez-Lachaud et al., 2004). However, this advantage depends greatly on whether or not the facultative hyperparasitoid in question has superior or at least comparable searching efficiency, fertility and intrinsic rate of population increase compared to the primary parasitoid (Pedersen and Mills, 2004), in addition to ability to utilize the immature stages of the intra-guild prey. Laboratory studies showed that $\mathrm{C}$. vestalis is a superior competitor to O. sokolowskii at intra-host level (Mahmood et al., 2003; Shi and Liu, 2003), as it uses physical combat of 1 st instar larvae and physiological suppression, i.e., due to polydnavirus and venom injected by the mother in the P. xylostella host during oviposition, to overcome interspecific competition (Bai et al., 2011). But, as C. vestalis larvae grow in size and get too close to the integument of the host, they may be vulnerable to direct parasitism by $\mathrm{O}$. sokolowskii (Mahmood et al., 2003; Shu-Sheng Liu, Zhejiang University, personal communication). Thus, $\mathrm{O}$. sokolowskii has a narrow window of opportunity to directly parasitize C. vestalis due to the restriction imposed by its virtually invisible ovipositor. This explains why direct exposure of $\mathrm{P}$. xylostella larvae containing $\mathrm{C}$. vestalis larvae to $\mathrm{O}$. sokolowskii yields lower proportion of secondary parasitism (Mahmood et al., 2003; Xue-Xin Chen, Zhejiang University, personal communication). In this study, O. sokolowskii was significantly more of a primary parasitoid than a hyperparasitoid, and its realized clutch size was significantly higher on pupae of $\mathrm{P}$. xylostella than of $\mathrm{C}$. vestalis, which suggests that if $\mathrm{O}$. sokolowskii cannot discriminate between unparasitized host larvae and host larvae parasitized by $\mathrm{C}$. vestalis, and adjusts its clutch size accordingly, parasitism of $\mathrm{P}$. xylostella larvae containing $\mathrm{C}$. vestalis larvae carries a high cost for its population density. Further, its impact on C. ves-talis population appeared random as it was not related to density of P. xylostella larvae. Thus, it is inconceivable that $\mathrm{O}$. sokolowskii actively searches for and parasitizes host larvae containing $\mathrm{C}$. vestalis larvae of vulnerable size, and avoid unparasitized hosts. At population level, the advantage of C. vestalis over $\mathrm{O}$. sokolowskii is due to faster generation time and higher fertility (Wang et al., 1999; Shi et al., 2002; Shi and Liu, 2003).

The positive influence of natural enemy diversity on biological control of insect pests was reported in several studies in recent years (Walde, 1994; Rosenheim, 1998; Wilson et al., 1999; Rodríguez and Hawkins, 2000; Rozdisky and Stone, 2001; Cardinale et al., 2003; Casula et al., 2006). However, to the best of my knowledge, the relationship between natural enemy diversity and population suppression of insect pests was never studied in the context of ecological disturbance from higher order consumers. This study showed that primary parasitoid species that are invulnerable to hyperparasitism can take over the function of vulnerable ones in communities with strong interspecific interactions. Therefore, a whole ecosystem approach that considers both direct and indirect effects of hyperparasitoids in primary parasitoid communities will improve our understanding of the net impact of hyperparasitism on biological control of insect pests.

\section{Acknowledgments}

I thank M.S. Mosiane, T.M. Mailula, M. Ngoato, P.H. Dikobe, M. Motsamai, and D. Pooe for technical assistance. The helpful discussions with K.V. Mawela and Dr. D.O. Simelane during preparation of this manuscript are highly appreciated. The study was financed by the Agricultural Research Council, the Department of Science and Technology, and the United States Agency for International Development (USAID) - CDR (Grant no. TA-MOOV-C18-055).

\section{References}

Agricola, U., Fisher, H.-U., 1991. Hyperparasitism in two newly introduced parasitoids, Epidinocarsis lopezi and Gyranusoidea tebygi (Hymenoptera: Encyrtidae) after their establishment in Togo. Bulletin of Entomological Research 81, 127-132.

Alam M.M., 1992. Diamondback moth and its natural enemies in Jamaica and some other Caribbean islands. In: Talekar, N.S. (Ed.), Diamondback Moth and Other Crucifer Pests: Proceedings of the Second International Workshop, December 1990. Asian Vegetable Research and Development Centre, Tainan. Taiwan, pp. 233-243

Araj, S.-E., Wratten, S., Lister, A., Buckley, H., 2009. Adding floral nectar to improve biological control: potential pitfall of the fourth trophic level. Basic and Applied Ecology 10, 554-562. 
Ayal, Y., Green, R.F., 1993. Optimal egg distribution among host patches for parasitoids subject to attack by hyperparasitoids. The American Naturalist 141, 120-138.

Bai, S.F., Li, X., Chen, X.X., Cheng, J.A., He, J.H., 2011. Interspecific competition between two endoparasitoids Cotesia vestalis (Hymenoptera: Braconidae) and Oomyzus sokolowskii (Hymenoptera: Eulophidae). Archives of Insect Biochemistry and Physiology 76, 156-167.

Boenisch, A., Petersen, G., Wyss, U 1997 . Influence of the hyperparasitoid Dendrocerus carpenteri on the reproduction of the grain aphid Sitobion avenae. Ecological Entomology 22, 1-6.

Borer, E.T., Briggs, C.J., Murdoch, W.W. Swarbrick, S.L., 2003. Testing intraguild predation theory in a field system: does numerical dominance shift along a gradient of productivity? Ecology Letters 6, 929-935.

Bourrchier, R.S. Nealis, V.G., 1992. Patterns of hyperparasitism of Cotesia melanoscela (Hymenoptera: Braconidae) in Southern Ontario. Environmental Entomology 21, 907-912.

Briggs, C.J., 1993. Competition among parasitoid species on a stage-structured host and its effect on host suppression. The American Naturalist 141, 372-397.

Brodeur, J, McNeil, J.N., 1992. Host behaviour modification by the endoparasitoid Aphidius nigripes: a strategy to reduce hyperparasitism. Ecological Entomology 17, 97-104.

Brodeur, J., 2000. Host specificity and trophic relationships of hyperparasitoids. In: Hochberg, M.R.. Ives, A.R. (Eds.), Parasitoid Population Biology. Princeton University Press, Princeton, New Jersey, pp. 163-183.

Cameron, P.J., Walker, G.P., 2002. Field evaluation of Cotesia rubecula (Hymenoptera: Braconidae), an introduced parasitoid of Pieris rapae'(Lepidoptera: Pieridae) in New Zealand. Environmental Entomology $31,367-374$.

Cardinale, B.L., Harvey, C.T., Gross, K., Ives, A.R., 2003. Biodiversity and biocontrol: emergent impacts of a multi-enemy assemblage on pest suppression and crop yield in an agroecosystems. Ecology Letters 6, 857-868.

Carew, W.P., Sullivan, D.J., 1993. Interspecific parasitism between two aphid hyperparasitolds, Dendrocerus carpenteri'(Hymenoptera: Megaspilidae) and Asaphes lucens (Hymenoptera: Pteromalidae). Annals of the Entomological Society of America 86,794-798.

Casula, P., Wilby, A., Thomas, M.B., 2006. Understanding biodiversity effects on prey in multi-enemy systems. Ecology Letters 9, 995-1004.

Chesson, $\mathrm{P}$, 1991. A need for niches? Trends in Ecology and Evolution 6, 26-28.

Chow, A., Mackauer, M., 1999. Host handling and specificity of the hyperparasitoid wasp, Dendrocerus carpenteri (Curtis) (Hym., Megaspilidae): importance of host age and species. Journal of Applied Entomology 123, 83-91.

Clausen C.P., 1972. Entomophagous Insects. Hahner publishing company, New York.

Cock, M.J.W., 1983. Introduction of parasites of Plutella xylostella (L.) into Republic of Cape Verde Islands. Project report, Commonwealth Institute of Biological Control.

Crawley, M.J., 1989. Insect herbivores and plant population dynamics. Annual Review of Entomology 34, 531-564.

Day, W.H., 2002. Biology, host preferences, and abundance of Mesochorus curvulus (Hymenoptera:

Ichneumonidae), a hyperparasite of Peristenus spp. (Hymenoptera: Braconidae) parasitizing plant bugs

(Miridae: Hemiptera) in alfalfa-grass forage crops. Annals of the Entomological Society of America 95, $218-222$.

DeBach, P., Rosen, D., 1991. Biological Control by Natural Enemies. Cambridge University Press, Cambridge.

Desouhant, E., Driessen, G., Lapchin, L., Wielaard, S., Bernstein, C., 2003. Dispersal between host populations in field conditions: navigation rules in the parasitoid Venturia canescens. Ecological Entomology 28, $257-267$.

Eichhorn, O., 1996. Experimental studies upon the parasitoid complex of the gypsy moth (Lymantria dispar L.) (Lep.: Lymantriidae) in lower host populations in Eastern Austria. Journal of Applied Entomology $120,205-212$.

Gichini, G., Löhr, B., Rossbach, A., Nyambo, B., Gathu, R., 2008. Can low release numbers lead to establishment and spread of an exotic parasitoid: the case of the diamondback moth parasitoid, Diadegma semiclausum (Hellén), in East A frica. Crop Protection 27, 906-914.

Godfray, H.C.J., 1994. Parasitoids: Behavioral and Evolutionary Ecology. Princeton University Press, New Jersey.

Grasswitz, T.R.', Reese, B.D., 1998. Biology and host selection behaviour of the aphid hyperparasitoid Alloxysta victrix in association with the primary parasitoid Aphidius colemani and the host aphid Myzus persicae. BioControl 43, 261-271.

Hairston, N.G., Smith, F.E., Slobodkin, L.G., 1960. Community structure, population control, and competition. The American Naturalist 94, 421-425.

Hawkins, B.A., 1994. Pattern and Process in Host-Parasitoid Interactions. Cambridge University Press, London.

Hawkins, B.A., Cornell, H.V., 1999. Theoretical Approaches to Biological Control. Cambridge University Press, Cambridge.

Höller, C., Borgemeister, C., Haart, H., Powell, W. 1993. The relationship between primary parasitoids and hyperparasitoids of cereal aphids: an analysis of field data. Journal of Animal Ecology 62, 12-21.

Jordaan, M., 1993. Brassicaceae. In: Arnold, T.H., De Wet, D.C. (Eds.) Plants of Southern Africa: Names and Distribution. Memoirs of the Botanical Survey of National Botanical Institute, South Africa, 62, pp. $313-322$.

Kahuthia-Gathu, R., Löhr, B., Poehling, H.M., Mbugua, P.K., 2009. Diversity, distribution and role of wild crucifers in major cabbage and kale growing areas of Kenya. Bulletin of Entomological Research 99, $287-297$.

Kellogg, S.K., Fink, L.S., Brower, L.P. 2003. Parasitism of native Luna moths, Actis luna (L.) (Lepidoptera: Saturniidae) by the introduced Compsilura concinnata (meigen) (Diptera: Tachinidae) in central Virginia, and their hyperparasitism by Trigonalid wasps (Hymenoptera: Trigonalidae). Environmental Entomology 32, 1019-1027.

Kfir, R. 1997. Parasitoids of Plutella xylostella (Lep.: Plutellidae) in South Africa: an annotated list. Entomophaga $42,517-52 \dot{3}$.

Lei, G.-C., Hanski, I., 1997. Metapopulation structure of Cotesia melitaerum, a specialist parasitoid of the butterfly Melitaea cinxia. Oikos 78, 91-100.

Liu, S.-S., Wang, X.-G., Shi, Z.-H., Gebremeskel, F.B., 2001. The biology of Diadromus collaris (Hymenoptera: Ichneumonidae), a pupal parasitoid of Plutella xylostella (Lepidoptera: Plutellidae), and its interactions with Oomyzus sokolowskii (Hymenoptera: Eulophidae). Bulletin of Entomological Research 91, 461-469.

Loreau, M., 2004. Does functional redundancy exist? Oikos 104, 606-611.

Mahmood, A.R., Liu, S.S., Shi, Z.H., Song, X.H., Zalucki, M.P., 2003. Lack of intraspecific biological variation between two geographical populations of Oomyzus sokolowskii (Hymenoptera: Eulophidae), a gregarious larvalpupal parasitoid of Plutella xylostella (Lepidoptera: Plutellidae). Bulletin of Entomological Research 93, 169-177.

Matsumoto, T., Iotika, T., Nishida, T. 2003. Cascading effects of a specialist parasitoid on plant biomass in a Citrus agroecosystem. Ecological Research 18, 651-659.

Moore, S.D., Kfir, R., 1995. Host preference of the facultative hyperparasitoid Tetrasticus howardi (Hym.: Eulophidae). Entomophaga 40, 69-76.

Mosiane, M.S., Kfir, R., Villet, M.H., 2003. Seasonal phenology of the diamondback moth, Plutella xylostella (L.) (Lepidoptera: Plutellidae), and its parasitoids on canola, Brassica napus (L.), Gauteng Province, South Africa. 
African Entomology 11, 277-285.

Müller, C.B.. Godfray, H.C.J. 1998. The response of aphid secondary parasitoids to different patch densities of their host. BioControl 43, 129-139.

Müller, C.B., Godfray, H.C.J.j 1999. Indirect interactions in aphid-parasitoid communities. Researches on Population Ecology 41, 93-106.

Müller, C.B., Adriaanse, I.C.T., Belshaw, R. Godfray, H.C.J., 1999. The structure of an aphid-parasitoid community. Journal of Animal Ecology 68, 346-370.

Murdoch W.W., Briggs, C.J., 1996. Theory for biological control: recent developments. Ecology 77, 2001-2013.

Nofemela, S.R., 2004. Studies on Parasitoids of the Diamondback Moth, Plutella xylostella (L.) (Lepidoptera: Plutellidae), in South Africa. MSc thesis, Rhodes University, Grahamstown.

Nofemela, R.S., Kfir, R, 2005. The role of parasitoids in suppressing diamondback moth, Plutella xylostella (L.) (Lepidoptera: Plutelilidae), populations on unsprayed cabbage in the North West Province of South Africa. African Entomology 13, 71-83.

Nofemela, R.S., Kfir, R., 2008. The pest status of diamondback moth and the role of Cotesia plutellae in suppressing the pest populations in South Africa. In: Shelton, A.M., Collins, H.L., Youjun, Z., Qingjun, W. (Eds.) The Management of Diamondback Moth and Other Crucifer Pests: Proceedings of "the Fitth International Workshop, 24-27 October 2006, Beijing, China Agricultural Science and Technology Press, China, pp. $239-249$.

Oishi, M., Sato, H., 2008. Guild structure and coexistence mechanisms in the parasitoid assemblage associated with a leafminer, Coptotriche japoniella (Lepidoptera: Tischeriidae), on an evergreen tree, Eurya japonica (Theaceae). Environmental Entomology 37, 1231-1240.

Pedersen, B.S., Mills, N.J., 2004. Single vs. multiple introduction in biological control: the roles of parasitoid efficiency, antagonism and niche overlap. Journal of Applied Ecology 41, 973-984.

Pérez-Lachaud, G., Batchelor, T.P., Hardy, I.C.W.. 2004. Wasp eat wasp: facultative hyperparasitism and intra-guild predation by bethylid wasps. Biological Control 30, 149-155.

Polis, G.A., Sears, A.L.W., Huxel, G.R., Strong, D.R., Maron, J., 2000. When is trophic cascade a trophic cascade? Trends in Ecology and Evolution 15, 473-476.

Price, P.W., 1972. Parasitoids utilizing the same host: adaptive nature of differences in size and form. Ecology 53, $190-195$

Rodríguez, M.Á., Hawkins, B.A., 2000. Diversity, function and stability in parasitoid communities. Ecology Letters 3, 35-40

Roltsch, W.J., Meyerdirk, D.E., Warkentin, R., Andress, E.R., Carrera, K., 2006. Classical biological control of the pink hibiscus mealybug, Maconellicoccus hirsutus (Green), in southern California. Biological Control 37, 155166

Rosen, D., 1981. The Role of Hyperparasitism in Biological Control: A symposium. Division of Agricultural Sciences, University of California Publication, 4103

Rosenheim, J.A., Kaya, H.K., Ehler, L.E., Marios, J.J., Jaffee, B.A., 1995. Intraguild predation among biological control agents: theory and evidence. Biological Control 5, 303-335.

Rosenheim, J.A., 1998. Higher-order predators and the regulation of insect herbivore populations. Annual Review of Entomology 43, 421-447

Rozdisky, I.D., Stone, L., 2001. Complexity can enhance stability in competitive systems. Ecology Letters 4, 397400.

Rutherford, M.C., Mucina, L., Lötter, M.C. Bredenkamp, G.J., et al., 2006. Savanna biome. In: Mucina, L.,

Rutherford, M.C.'(Eds.), The Vegetation of South Africa, Lesotho and Swaziland. South African National Biodiversity Institute, Pretoria.

Schmitz, O.J., Hamback, P.A.. Beckerman, A.P., 2000. Trophic cascades in terrestrial systems: a review of the effects of carnivore removals on plants. The American Naturalist 155, 141-153.

Schooler, S.S., Ives, A.R., Harmon, J., 1996. Hyperparasitoid aggregation in response to variation in Aphidius ervi host density at three spatial scales. Ecological Entomology $21,249-258$.

Schooler, S.S., De Barro, P., Ives, A.R., 2011. The potential for hyperparasitism to compromise biological control: why don't hyperparasitoids drive their parasitoid hosts extinct? Biological Control 58, 167-173.

Schwarz, M., Shaw, M.R., 2000. Western Palearctic Cryptinae (Hymenoptera: Ichneumonidae) in the national museums of Scotland, with nomenclatural changes, taxonomic notes, rearing records and special reference to the British check list. Part 3. Tribe Phygadeuontini, subtribes Chiroticina, Acrolytina,Hemitelina and Gelina (excluding Gelis), with descriptions of new species. Entomologist's Gazette 51, 147-186.

Shi, Z.-H., Liu, S.-S., Li, Y.X., 2002. Cotesia plutellae parasitizing Plutella xylostella: host-age dependent parasitism and its effects on host development and food consumption. BioControl 47, 499511

Shi, Z.-H., Liu, S.-S., 2003. Interspecific interactions between Cotesia plutellae and Oomyzus sokolowskii, two major parasitoids of diamondback moth, Plutella xylostella. Chinese Journal of Applied Ecology 14,949-954.

Smith, T.J. 2004. The Diamondback Moth' Plutella xylostella (L.) (Lepidoptera: Plutellidae) and its Biological Control in the Eastern Cape Province, South Africa. PhD Dissertation, Rhodes University, Grahamstown, South Africa.

Statistica, 2012. Statistica 10 for Windows. Statistica Enterprise System Technology, Tulsa, OK, USA.

Sullivan, D.J., Völk1, W.. 1999. Hyperparasitism: multitrophic ecology and behaviour. Annual Review of Entomology 44, 291-3ï5.

Talekar, N.S., Hu, W.J., 1996. Characteristics of parasitism of Plutella xylostella (Lep.: Plutellidae) by Oomyzus sokolowskii (Hym.: Eulophidae). Entomophaga 41, 45-52.

Tanaka, S., Ohsaki, N., 2006. Behavioral manipulation of host caterpillars by the primary parasitoid wasp Cotesia glomerata (L.) to construct defensive webs against hyperparasitism. Ecological Research 21, 570-577.

Tanaka, S., Ohsaki, N., 2009. Does manipulation by the parasitoid wasp Cotesia glomerata (L.) cause attachment behaviour of host caterpillars on cocoon clusters? Ethology 115, 781-789.

Ullyett, G.C., 1947. Mortality factors in populations of Plutella maculipennis Curtis (Tinedae: Lep.), and their relation to the problem of control. Entomology Memoirs, 2. Department of Agriculture and Forestry, Union of South Africa, pp. 77-202.

Vandermeer, J., Carvajal, R., 2001. Metapopulation dynamics and the quality of the matrix. The American Naturalist 158, 211-220.

Van Driesche, R.G., Bellows, T.S., Elkington, J.S., Gould, J.R., Ferro, D.N., 1991. The meaning of percentage parasitism revisited: solutions to the problems of accurately estimating total losses from parasitism.

Environmental Entomology 20, 1-7.

Van Veen, F.J.F., Rajkumar, A., Müller, C.B., Godfray, H.C.J., 2001. Increased reproduction by pea aphids in the presence of secondary parasitoids. Ecological Entomology 26, 425-429. 
Veddeler, D., Tylianakis, J., Tscharntke, T., Klein, A.-M., 2010. Natural enemy diversity reduces temporal variability in wasp but not bee parasitism. Oecologia 1'62, 755-762.

Waladde, S.M., Leutle, M.F., Villet, M.H., 2001. Parasitism of Plutella xylostella (Lepidoptera: Plutellidae): field and laboratory observations. South African Journal of Plant and Soil 18, 32-37.

Walde, S.J. 1994. Immigration and the dynamics of a predator-prey interaction in biological control. Journal of Animal Ecology 63, 337-346.

Walter, G.H., Abeeluck, D., 2006. Confirmation of the existence of alloparasitoids in nature - host relationships of an Âustralian Coccophagus species that parasitizes mealy bugs. Entomologia Experimentalis et Applicata 118, 97-103.

Wang, X.-G., Liu, S.-S., Guo, S.-J., Lin, W.-C. 1999. Effects of host stages and temperature on population parameters of Oomyzus sokolowskii, a larval-pupal parasitoid of Plutella xylostella. BioControl 44, 391-402

Weseloh, R.M., 1986. Hyperparasites of the gypsy moth (Lepidoptera: Lymantriidae) field attack patterns of Cotesia melanoscela (Hymenoptera: Braconidae) at different host densities and on different-sized host clumps. Annals of the Entomological Society of America 79, 308-311

Wilson, W.G., Osenberg, C.W., Schmitt, R.J., Nisbet, R.M., 1999. Complementary foraging behaviour allow coexistence of two consumers. Ecology 80,2358-2372. 